\title{
Estudio preliminar de las escorias y escorificaciones del yacimiento metalúrgico de la Edad del Bronce de Peñalosa (Baños de la Encina, Jaén)
}

\author{
Preliminary study of slags and slaggy layers on ceramics from the Bronze Age \\ metallurgical site of Peñalosa (Baños de la Encina, Jaén)
}

\author{
Auxilio Moreno Onorato (*) \\ Francisco Contreras Cortés $(*)$ \\ Martina Renzi (**) \\ Salvador Rovira Llorens $(* * *)$ \\ Heber Cortés Santiago (*)
}

\section{RESUMEN}

Este trabajo ofrece una revisión de los procesos metalúrgicos llevados a cabo en el asentamiento I, de acuerdo con los resultados del reciente estudio analítico realizado sobre los restos de escorias y escorificaciones de cerámicas metalúrgicas. A partir de estos análisis, que nos permiten la identificación de los minerales procesados y de las características de la producción metálica obtenida, se aportan nuevas perspectivas para determinar el tipo de tecnología desarrollada y las condiciones en las que se llevaron a cabo los diferentes procesos. En este sentido destaca la utilización de minerales de cobre muy ricos en plomo, que proporcionan altas cantidades de compuestos de plomo en las vasijas cerámicas y en productos secundarios como escorias y restos de fundición. Se completa el estudio con el análisis de la tipología y tecnología de las vasijas cerámicas de uso metalúrgico.

\footnotetext{
ABSTRACT

This paper offers a revision of the metallurgical processes carried out at the settlement on the basis of a recent analytical study of slags and slagged metallurgical ceramics. These analyses allowed us to identify the ores

(*) Universidad de Granada. Departamento de Prehistoria y Arqueología. Campus Universitario de Cartuja, s/n. 18071 Granada. Correo electrónico: auxiliomoreno@ugr.es; fccortes@ugr.es; titocort@yahoo.com.

(**) CSIC. Instituto de Historia. C/ Albasanz, 26-28. 28037 Madrid. Correo electrónico: martina.renzi@cchs.csic.es.

(***) C/Espartero, 50-2. ${ }^{\circ}$-pta 6. 46450 Benifaió (Valencia). Correo electrónico: s_rovirallorens@hotmail.com.

Recibido: 15-III-2010; aceptado: 24-V-2010.
}

processed and the characteristics of this metal production. Therefore, the results obtained provide new perspectives to determining what type of technology was developed and the working conditions of the different processes carried out at the site. In this sense, the use of lead-rich copper ores stands out in explaining the presence of high quantities of lead compounds detected in various metallurgical ceramics and in secondary products, like slags and melting wastes. The present study also includes typological and technological analysis of metallurgical ceramic vessels.

Palabras clave: Península Ibérica; Prehistoria Reciente; Cultura del Argar; Arqueometalurgia; Tecnología metalúrgica; Minas prehistóricas; Vasijas de reducción; Crisoles.

Key words: Iberian Peninsula; Recent Prehistory; Argaric Culture; Archaeometallurgy; Metallurgical technology; Prehistoric mines; Smelting crucibles; Crucibles.

\section{INTRODUCCIÓN}

El yacimiento arqueológico de Peñalosa (Baños de la Encina, Jaén; Fig. 1) se sitúa en un espolón sobre el valle del río Rumblar, actualmente sumergido en parte por las aguas del embalse del mismo nombre (Fig. 2). Este yacimiento ha jugado un papel importante en la valoración cultural de la Edad del Bronce del mediodía de la Península Ibérica, al ser considerado como uno de los poblados más septentrionales de la expansión de la Cultura del Argar en busca de los filones meta- 


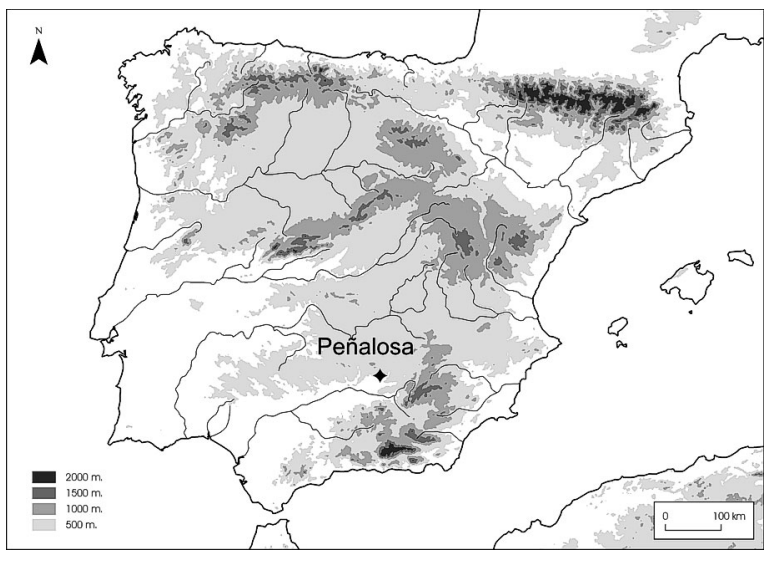

Fig. 1. Localización del yacimiento de la Edad del Bronce de Peñalosa (Baños de la Encina, Jaén).

líferos de Sierra Morena y ha sido objeto en los últimos años de varios proyectos de investigación (Contreras 2000; Contreras y Cámara 2002).

Se inserta en la cuenca baja y media-alta del río Rumblar, territorio que pone en contacto el frente meridional de Sierra Morena con la vega del Guadalquivir, en una zona dominada por el paisaje de dehesa y el dominio litológico de la pizarra, quedando como únicos suelos aprovechables los formados por los aportes erosivos sobre la cuenca del río Rumblar y la desembocadura de los ríos Pinto y Grande. Aparte del uso agro-silvo-pastoril, hay que destacar la presencia de los filones de cobre más importantes de la provincia.

Estos filones de cobre fueron posiblemente la causa de la rápida colonización que tuvo lugar en el Bronce Pleno, en torno al 1800 a.C.; se crearon una serie de asentamientos de nueva planta, de similares características arquitectónicas y con idéntica cultura material adscribibles a la norma argárica: patrones de asentamiento en cerros escarpados, urbanismo en terrazas artificiales, poblados con acrópolis fortificadas y murallas con bastiones, enterramientos individuales o dobles bajo las casas, nuevas formas cerámicas como copas, vasos carenados, y tipos metálicos novedosos con hallazgos de armas como espadas, puñales y hachas (Contreras 2004).

Estos poblados además presentan una característica importante: la explotación sistemática de minerales de cobre. Se han documentado varias minas con claros restos arqueológicos de su explotación en la Edad del Bronce, como martillos de piedra para extraer el mineral. Por otra parte, en distintos yacimientos de este valle se han recogido cerámicas metalúrgicas que muestran una actividad intensiva a lo largo del Bronce Pleno (Contreras y Moreno e.p.).

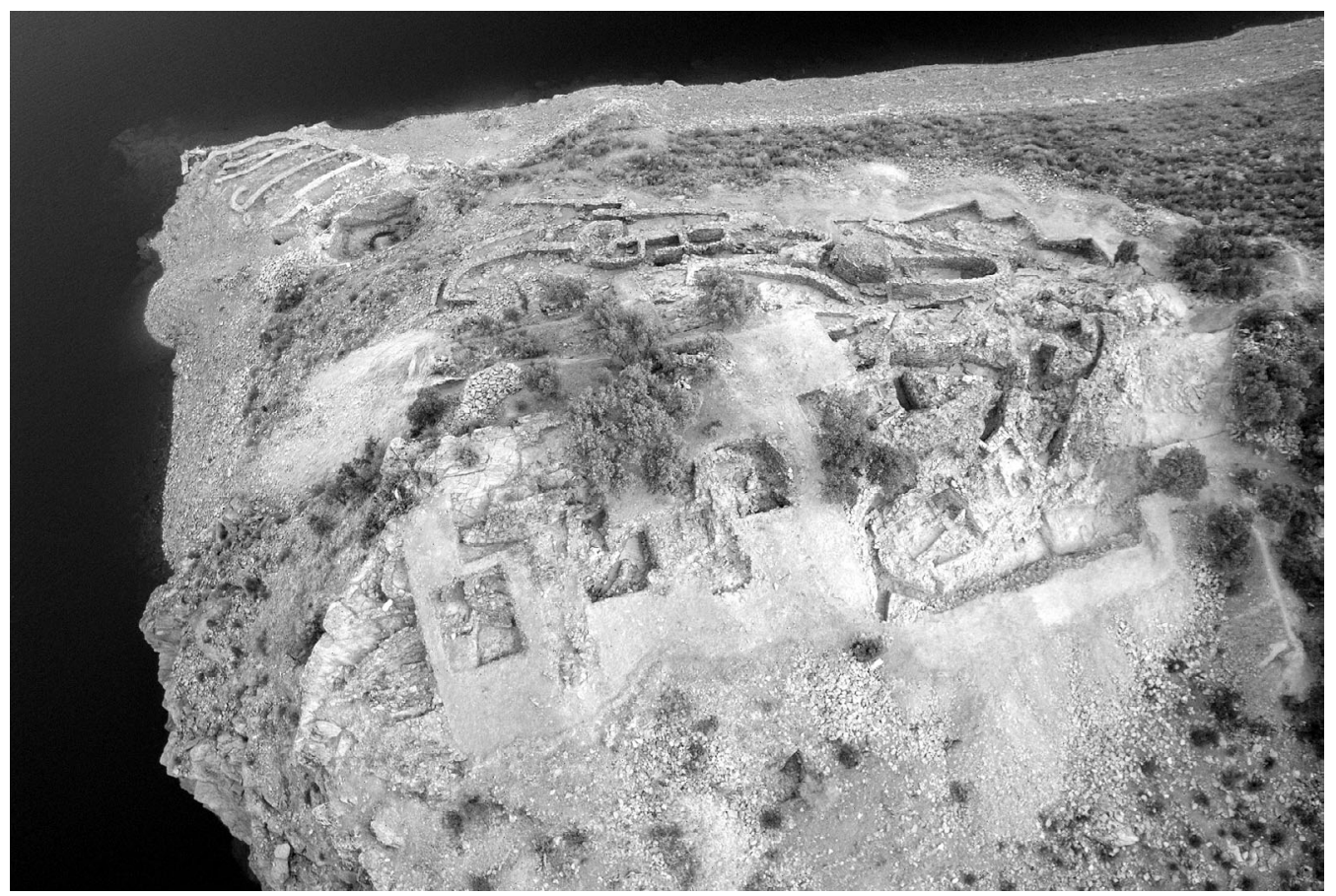

Fig. 2. Vista aérea del poblado de la Edad del Bronce de Peñalosa (Baños de la Encina, Jaén).

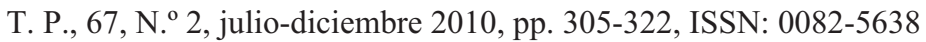
doi: $10.3989 /$ tp.2010.10041 


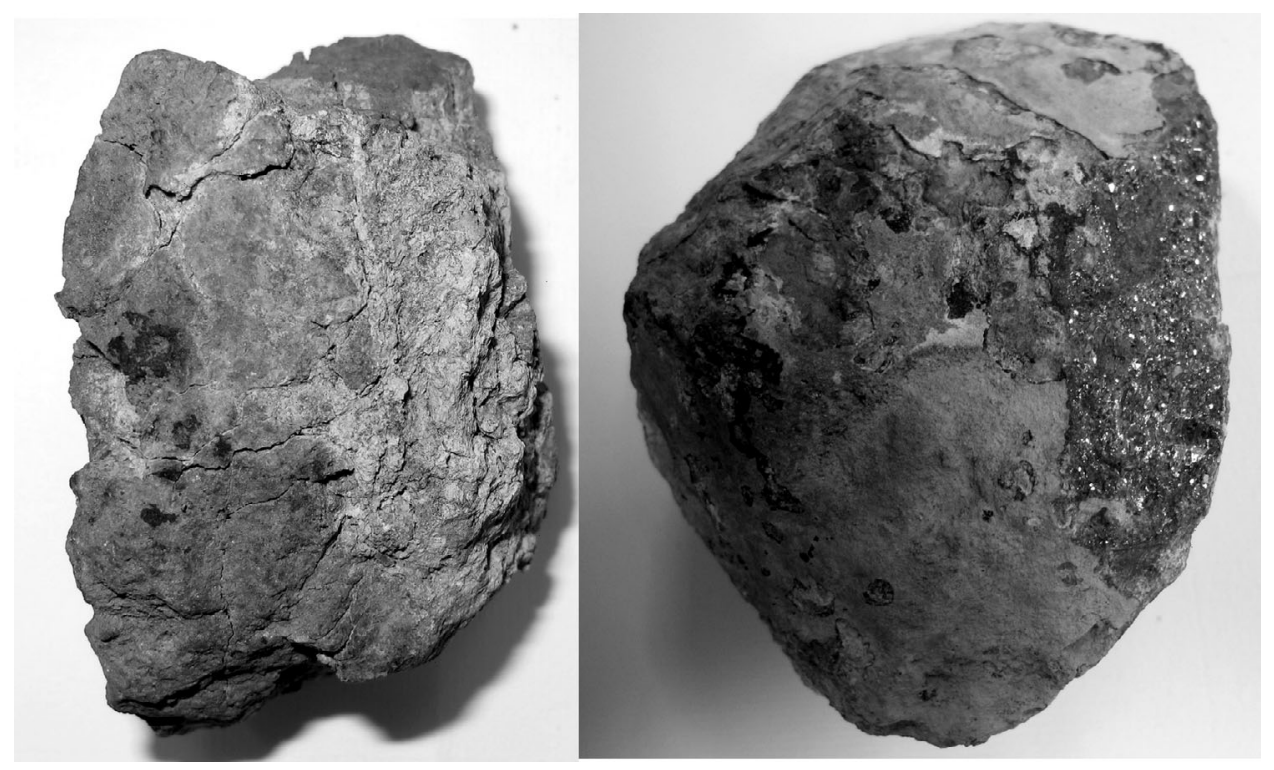

Fig. 3. Nódulos de minerales de cobre (a la izquierda) y de plomo (a la derecha) procedentes del yacimiento de la Edad del Bronce de Peñalosa (Baños de la Encina, Jaén).

Las dataciones correspondientes a la máxima expansión del poblado (Fase IIIA) se sitúan en fechas alrededor del $1750 \mathrm{cal}$ a.C., con el abandono definitivo del poblado después del $1550 \mathrm{cal}$ a.C. (Contreras et al. 2004: 35).

Una de las conclusiones que se extrae de la distribución de los materiales relacionados con la metalurgia en Peñalosa es que, si bien los hallamos en todos los espacios materiales vinculados con esta actividad, la proporción es altamente variable. La mayor parte de los productos metalúrgicos, excepto los elementos manufacturados, se concentra en espacios descubiertos o en espacios inmediatos a ellos. De hecho, en la mayoría de los casos, estos espacios descubiertos son de pequeñas dimensiones y se hallan al límite de las zonas cubiertas de las que están separados por pequeños tabiques o por alineaciones de hoyos de poste y estructuras murarias que configuran pequeños patios al interior de complejos estructurales más amplios (Contreras et al. 1997; Moreno 2000).

\section{LOS MINERALES DE PEÑALOSA Y SU ENTORNO}

El registro arqueológico ha sido pródigo en muestras de minerales metalíferos, con más de 600 muestras, de las cuales aproximadamente 90 corresponden a mineral de plomo (galena). La metalurgia de Peñalosa ya fue estudiada en una primera fase (campañas de 1986, 1987, 1989 y 1991) (Moreno 2000) pero las nuevas campañas (2001, 2005 y 2009) han proporcionado numerosos materiales arqueometalúrgicos. Con la incorporación al proyecto de S. Rovira y M. Renzi, se ha iniciado una revisión de los resultados analíticos de los materiales estudiados anteriormente y se ha ampliado el muestreo para realizar nuevos análisis.

En este trabajo se presentan de manera preliminar los nuevos datos obtenidos. Debido a las limitaciones del espacio disponible, no se presentarán la posición estratigráfica y la ubicación topográfica de las muestras estudiadas, dejando los datos de tipo espacial y cronológico para estudios posteriores de mayor detalle.

En general, los minerales encontrados son fragmentos de tamaño pequeño y mediano -como en el caso de la galena- con signos de fractura en las superficies (Fig. 3). Unas 70 muestras de dichos minerales han sido analizadas con un espectrómetro de fluorescencia de rayos X (XRF-ED) en el laboratorio del Museo Arqueológico Nacional (1). Mediante estos análisis se ha comprobado que se trata generalmente de minerales polimetálicos en cuya composición destacan dos metales

(1) Espectrómetro Metorex XMET-920, con fuente de ${ }^{241} \mathrm{Am}$ de $20 \mathrm{mCi}$. 
principales: cobre y plomo. Aunque algunas muestras contienen cantidades apreciables de hierro en la ganga, en general son minerales pobres en compuestos ferruginosos. En la ganga predominan el cuarzo y los silicatos, en algunos casos asociados con baritina; estos elementos no son detectables por las características del espectrómetro utilizado pero a simple vista se distingue con claridad la naturaleza silícica de la roca encajante. Algunos minerales contienen también arsénico, habiéndose medido proporciones $\mathrm{Cu} / \mathrm{As}$ de hasta 30/10.

Los minerales metalíferos se pueden repartir con bastante precisión en dos grupos: las menas cupríferas, en las que el cobre es el compuesto mineral que predomina, y las menas plumbocupríferas con cantidades importantes de plomo, habitualmente presente como galena o sus correspondientes compuestos oxidados. La constatación del laboreo y aprovechamiento de minerales plumbo-cupríferos en un contexto arqueometalúrgico de Bronce Pleno es una novedad importante dentro del panorama de la metalurgia de la Península Ibérica hasta ahora conocido. Así, pues, la actividad metalúrgica de Peñalosa parece que estuvo basada en el aprovechamiento de recursos minerales de cobre y plomo-cobre extraídos de mineralizaciones marcadamente diferentes. La presencia de sulfuros metálicos junto a compuestos oxidados en muchas de las muestras de minerales hace pensar en una metalurgia de fahl ores (Craddock 1995: 28). De este tipo de metalurgia sólo teníamos algún indicio indirecto que considerábamos excepcional y no intencionado, como es el caso de algunos pocos minerales y escorificaciones de los niveles calcolíticos de Almizaraque (Cuevas del Almanzora, Almería) (Müller et al. 2004: 48, 51), o el de la gran vasija de reducción de La Ceñuela (Murcia), atribuida al Calcolítico Reciente (Rovira 2002: 90-91) o quizás más adecuadamente a la fase de transición a la Cultura Argárica.

Como ya se ha mencionado anteriormente, Peñalosa es un enclave ubicado dentro de un amplio metalotecto de Sierra Morena. Los análisis de isótopos de plomo realizados sitúan el mineral hallado en sus complejos estructurales como procedente de tres posibles fuentes (Hunt et al. e.p.). Dos de ellas se corresponden con sendas minas localizadas en los alrededores del asentamiento El Polígono y José Martín Palacios quedando aún por localizar la tercera fuente.
En la Sierra Morena jienense la Mina de El Polígono es uno de los ejemplos más claros de trabajos antiguos de extracción desde la época calcolítica (Arboledas et al. 2006), ya descrita por Domergue (1987: 264) en las cercanías de Baños de la Encina (Jaén). Allí, además de constatar la explotación minera de cobre y plomo moderna y antigua, existen restos de cantería de la arenisca Triásica. Se trata de pequeñas calicatas que presentan fuertes concentraciones de malaquita y azurita y que parecen remontarse a una explotación prehistórica atendiendo a los restos arqueológicos recuperados: una hoja de sílex de filiación cultural claramente calcolítica y una docena de martillos mineros de piedra junto con algunas hachas, muy posiblemente de origen argárico. Esta mina habría sido explotada desde la Edad del Cobre, encontrándose además en el borde del Piedemonte, en la zona de contacto con la Depresión Linares-Bailén, justo entre dos poblados de esta época, el Cerro del Tambor y el Castillo de Baños de la Encina (Contreras et al. 2005a: 27; Contreras et al. 2005b: 118).

La segunda mina, la de José Martín Palacios (Baños de la Encina, Jaén), cuenta con varios pozos y vertederos que fueron explotados tanto en época argárica como romana. Durante su prospección y posterior levantamiento topográfico, sobre las escombreras asociadas a unos socavones se hallaron dos martillos de minero con ranura central de enmangue (Fig. 4) de igual tipología a los recuperados en el yacimiento de Peñalosa (Contreras et al. 2005a: 28; Contreras et al. 2005b: 119). La prospección geoeléctrica llevada a cabo en esta mina muestra la posibilidad de que

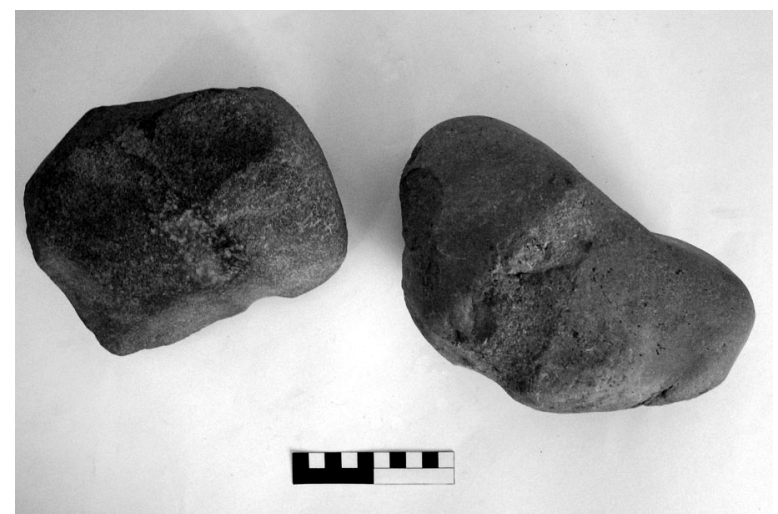

Fig. 4. Martillos de minero procedentes de las minas de José Martín Palacios y El Polígono (Baños de la Encina, Jaén). 
existan una serie de galerías, colmatadas en la actualidad, siendo nuestro deseo su excavación en el futuro (2).

Como apuntábamos, un pequeño lote de muestras de minerales de las minas de José Martín Palacios y El Polígono ha sido analizado utilizando el mismo método empleado para los fragmentos de minerales encontrados en el yacimiento. Según los resultados obtenidos, se trata de dos mineralizaciones marcadamente distintas: la de José Martín Palacios es predominantemente cuprífera y la de El Polígono plumbo-cuprífera. La figura 5 muestra gráficamente esa clara diferencia entre los dos grupos de minerales y, lo más interesante, cómo los minerales de las dos minas prospectadas se distribuyen perfectamente dentro del conjunto de Peñalosa conservando la partición global en dos grupos característicos.

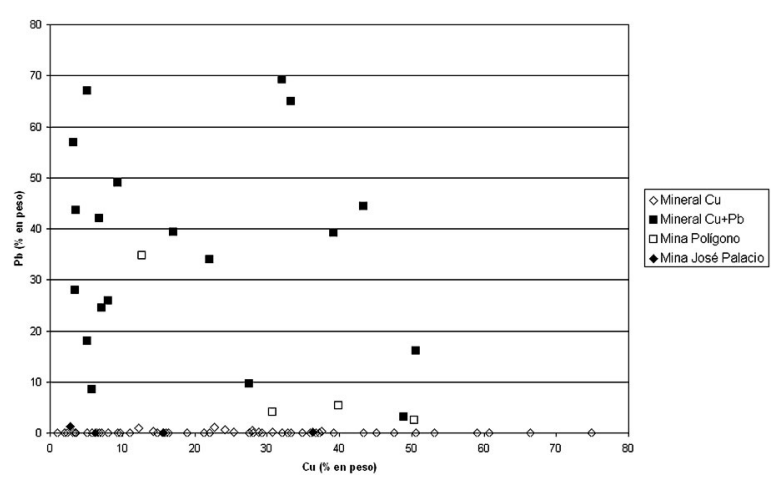

Fig. 5. Representación gráfica de las relaciones cobre-plomo de los minerales de Peñalosa y de dos minas prospectadas, las minas de José Martín Palacios y la de El Polígono (Baños de la Encina, Jaén).

Con el fin de profundizar en la posible procedencia geográfica de los minerales de Peñalosa, se han analizado los isótopos de plomo de varias muestras recogidas en el yacimiento en las citadas minas (3). Los resultados obtenidos junto con la representación gráfica de las relaciones isotópicas se publicarán en el Homenaje a Claude Do-

(2) La prospección geofísica eléctrica fue llevada a cabo en agosto del 2005 por J.A. Peña y T. Teixidó, miembros del Área de Prospección Geofísica del Instituto Andaluz de Geofísica de la Universidad de Granada.

(3) Los análisis de isótopos de plomo han sido realizados en la Universidad del País Vasco por medio de un espectrómetro de masas con fuente de ionización térmica (TIMS). Agradecemos al Dr. M.A. Hunt Ortiz la interpretación de los resultados analíticos. mergue celebrado en León en 2008 (Hunt et al. e.p.). En ella se observa un fuerte agrupamiento entre los minerales del contexto arqueológico y las mineralizaciones, como las representadas por las minas de José Martín Palacios y El Polígono. El número de muestras analizadas es todavía reducido para caracterizar las mineralizaciones por completo, pero estos resultados preliminares son extraordinariamente sugestivos y animan a efectuar más análisis en un futuro próximo.

Las minas prospectadas están muy alteradas por los trabajos modernos, particularmente la de El Polígono que ha estado en explotación hasta hace relativamente pocos años. Sin embargo, algunos fragmentos de mineral recogidos en el yacimiento de Peñalosa han proporcionado datos relevantes acerca de la técnica extractiva utilizada por los mineros. Se trata de fragmentos que presentan numerosas fisuras en cuyo interior se aprecian formaciones globulares (burbujas) cuando se observan detenidamente con una lupa binocular (Fig. 6). Estos rasgos sugieren que el mineral ha estado sometido a temperaturas relativamente altas, lo cual nos lleva a pensar en el método de extracción por fuego (firesetting) (Craddock 1995: 33-37). Este método consiste en provocar un fuego intenso en el frente de la labor minera y, cuando la pared rocosa ha alcanzado una temperatura estimada suficiente por el minero, en enfriarla bruscamente arrojando sobre ella gran cantidad de agua. El enfriamiento brusco (quen-

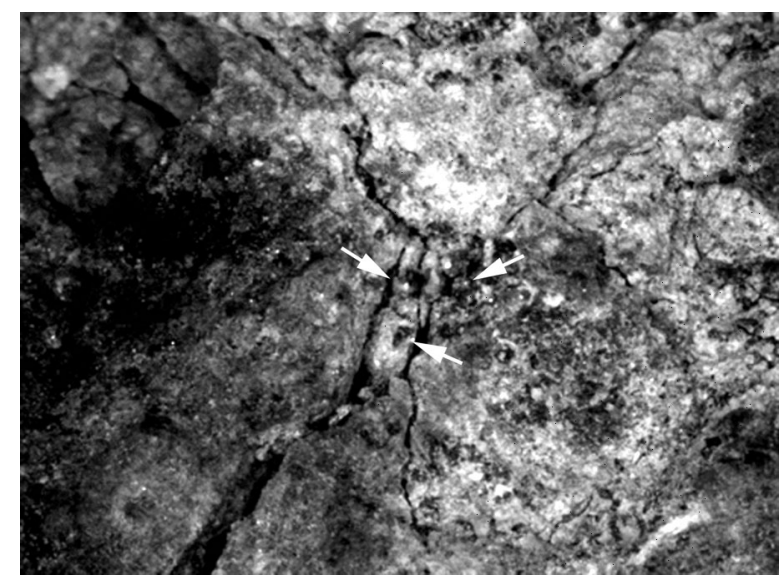

Fig. 6. Detalle de un fragmento de mineral procedente del yacimiento de la Edad del Bronce de Peñalosa (Baños de la Encina, Jaén) mostrando el característico agrietamiento por efecto del arrancamiento por fuego. Las flechas señalan pequeñas formaciones globulares por reacción térmica. 


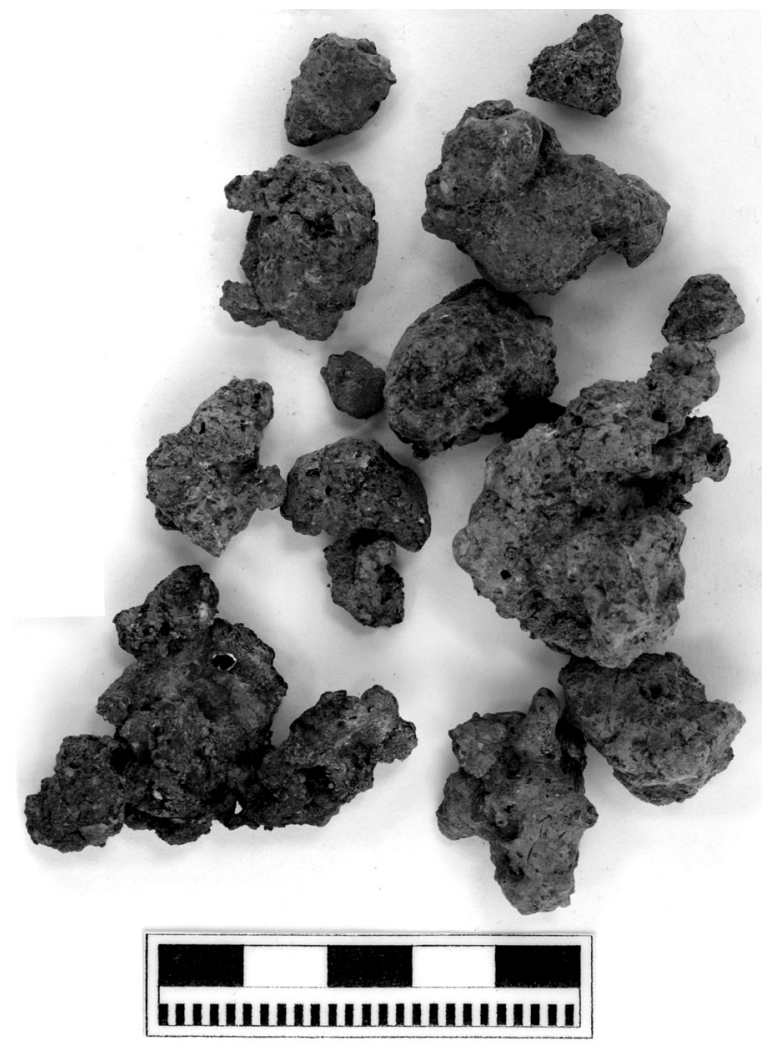

Fig. 7. Nódulos de escorias de cobre procedentes del yacimiento de la Edad del Bronce de Peñalosa (Baños de la Encina, Jaén).

ching) provoca grandes tensiones en la roca que llevan al agrietamiento e incluso a producir desprendimientos por estallido. El frente de la labor queda fisurado y resulta sencillo para el minero extraer el mineral golpeándolo con unas mazas de piedra.

La extracción con fuego es una técnica minera antigua que ha estado en uso en algunas minas hasta finales del siglo XIX. Hay pocas pero sólidas evidencias de su empleo en época prehistórica, por ejemplo, hace tiempo se descubrió su uso en la Edad del Bronce en los criaderos de minerales de Mitterberg (Austria) (Pittioni 1951). Timberlake (2003) también propone que esta técnica fue utilizada en las minas de Copa Hill y Cwmystwyth (Gales). Finalmente, cabe recordar por su gran antigüedad la mina calcolítica de Pioch Farrus IV (Cabrières, Francia) (Castaing et al. 2005). Por lo que respecta a la Península Ibérica, se ha detectado en las minas prehistóricas de la región asturiana (Blas 2005: 198). Las muestras de minerales de Peñalosa serían un testimonio, aunque indirecto, de la utilización de este procedimiento minero en Sierra Morena.

\section{LAS ESCORIAS DE PEÑALOSA}

En Peñalosa se ha recogido también un número importante de fragmentos de escorias de cobre, alrededor de 150. Generalmente, se han encontrado dispersas en los suelos arqueológicos, sin que se haya localizado ninguna acumulación importante. Suelen ser fragmentos pequeños, de varios centímetros, a menudo con signos de fragmentación en la superficie (Fig. 7).

Han sido analizadas 45 muestras por XRF para obtener una primera aproximación de su composición elemental. Al igual que se ha comprobado con los minerales, hay dos grupos: las escorias que no contienen cantidades importantes de plomo y las que son plomadas. Esta primera impresión evidencia la importancia determinativa de la materia prima procesada y es un primer indicio del uso de una tecnología de reducción directa de los minerales cupríferos.

De este grupo de escorias se han seleccionado 18 para un estudio más detallado por microscopía electrónica de barrido (MEB) (4).

En todos los casos se trata de escorias inmaduras, de composición heterogénea, con abundante sílice libre, que corresponden a sistemas físico-químicos no en equilibrio, producto de la reducción directa del mineral sin adición de fundentes. En el material fundido se suele encontrar una matriz silicatada en la que se hallan embebidas las bolas de metal que se han formado. Es frecuente encontrar relictos del mineral original o transformaciones de éste en cuprita sin reducir, delafosita si hay óxido de hierro en la ganga y formaciones cristalinas de hedenbergita, melilita, akermanita, wollastonita $u$ otros silicatos de la serie, así como magnetita. Las figuras 8 y 9 resultan muy ilustrativas de la aludida heterogeneidad de las escorias de Peñalosa.

(4) Los análisis MEB han sido realizados en los laboratorios del Museo de Ciencias Naturales del CSIC de Madrid utilizando un microscopio Fei Inspect con detector de electrones secundarios, electrones retrodispersados y un detector de Catodoluminiscencia Mono CL Gatan, y que dispone de un sistema de análisis integrado Oxford Instruments Analytical-Inca. El equipo ha sido operado por las microscopistas Marta M. Furió y Laura Tormo. 


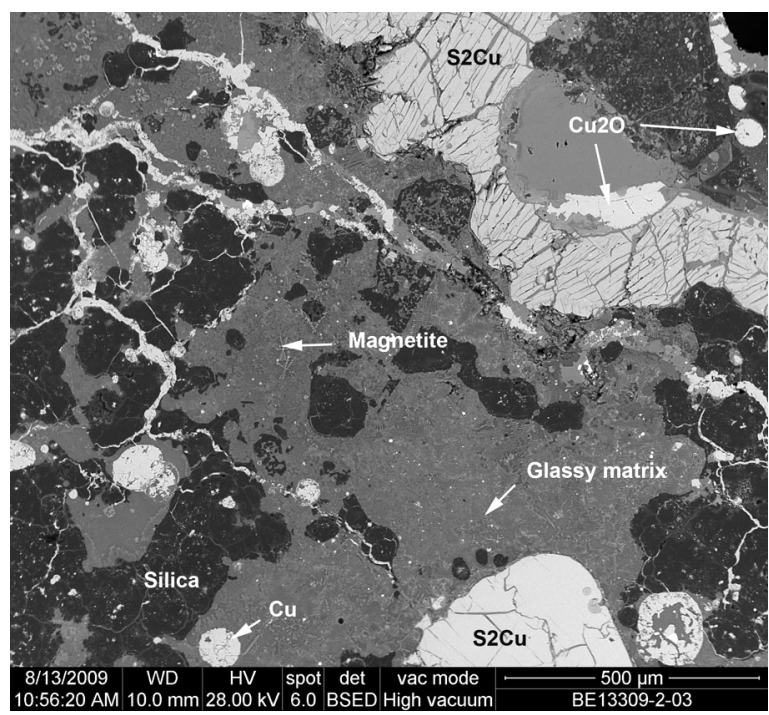

Fig. 8. Imagen obtenida en el MEB (electrones retrodispersados) de la escoria BE13309-2 procedente de Peñalosa. Obsérvese la presencia de relictos de mineral original $\left(\mathrm{Cu}_{2} \mathrm{~S}\right.$, sulfuro de cobre), sílice libre (silica) y una matriz fundida (glassy matrix) que contiene abundante magnetita (magnetite) en dispersión. Se han formado bolitas de cobre (copper), algunas oxidadas secundariamente a cuprita $\left(\mathrm{Cu}_{2} \mathrm{O}\right)$.

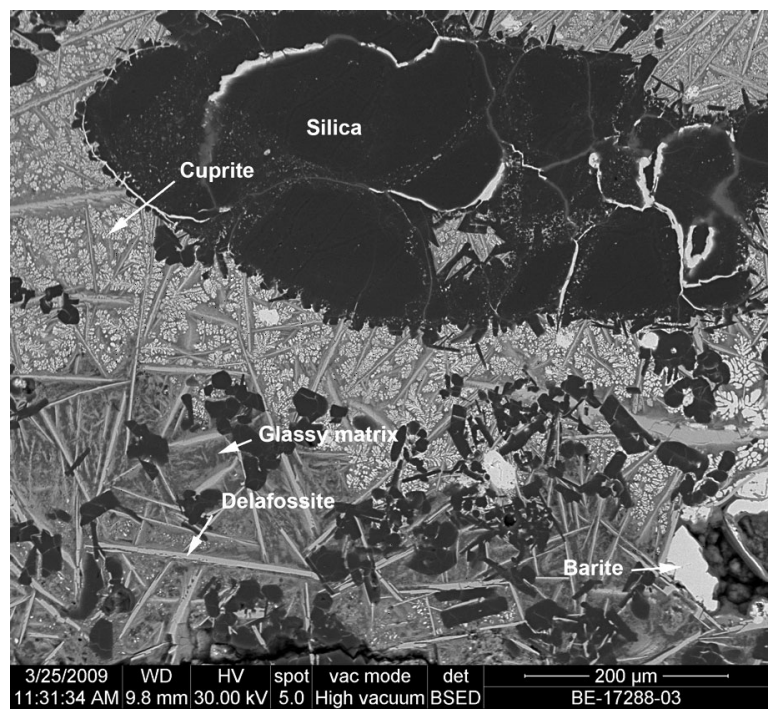

Fig. 9. Imagen obtenida en el MEB (electrones retrodispersados) de la escoria BE17288 procedente de Peñalosa. Obsérvese la presencia de sílice libre (silica) y la abundancia de placas seccionadas de delafosita (delafossite) en un campo con abundantes rosetas de cuprita (cuprite) dendrítica. La matriz vítrea (glassy matrix) es escasa. También se observa una inclusión de baritina (barite).

Raramente se detecta fayalita, y cuando existe está confinada en algunos microdominios dentro de la escoria (Fig. 10).

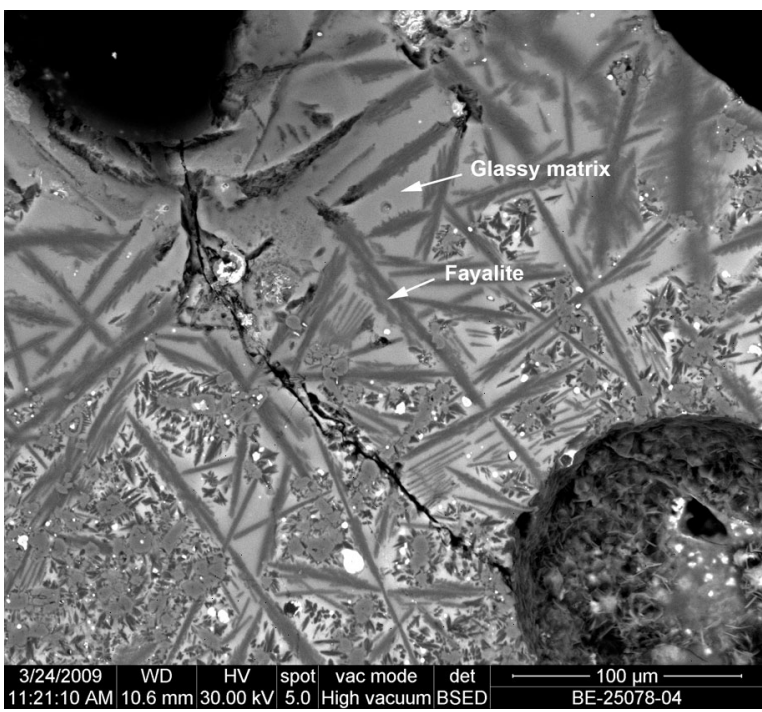

Fig. 10. Imagen obtenida en el MEB (electrones retrodispersados) de la escoria BE25078 procedente de Peñalosa. Obsérvese la formación de cristales plumiformes de fayalita (fayalite) en una matriz vítrea (glassy matrix). Los puntos blancos son cobre metálico.

Todas estas características se encuentran en las escorias inmaduras, ya bien conocidas en España y en otras regiones del Viejo Mundo desde época calcolítica, y que nos remiten a una metalurgia primaria de obtención de cobre bruto utilizando fuegos abiertos y vasijas de reducción como reactores. En esas circunstancias termoquímicas las condiciones redox del sistema son muy variables, a veces oxidantes (lo que propicia la formación de magnetita y delafosita, por ejemplo, si hay hierro suficiente en el sistema), a veces reductoras logrando la formación de metal y de fayalita si hay hierro en el aporte de la ganga.

Además de hablarnos de las condiciones redox del reactor, ciertos componentes de la escoria aportan datos térmicos de interés. Así, tanto la cuprita $\left(\mathrm{Cu}_{2} \mathrm{O}\right)$ como la calcosina $\left(\mathrm{Cu}_{2} \mathrm{~S}\right)$ funden a temperaturas del orden de $1.200^{\circ} \mathrm{C}$. Su presencia como glóbulos esféricos secundarios o en estructuras dendríticas (véase, por ejemplo las figuras 8 y 9) indican que la cámara de reacción estuvo a temperaturas en torno a esa cifra.

Lo que verdaderamente hace original la metalurgia de Peñalosa es el aprovechamiento de minerales cobre-plomo, que sin duda son abundantes en los metalotectos de Sierra Morena. Las escorias cobre-plomo resultantes de su reducción se caracterizan porque el material fundido que forma la matriz es un silicato complejo con mu- 
cho plomo: un vidrio al plomo. La figura 11 reproduce el espectro de los elementos químicos que constituyen la matriz de la escoria BE25078 (Fig. 10) y que definen un silicato complejo de plomo, hierro, calcio, aluminio y bario. El plomo se comporta de dos modos diferentes durante la reducción del mineral plumbo-cuprífe- ro. En unos casos pasa a la escoria formando la matriz vítrea, y el metal que se obtiene es cobre con algo de hierro en su composición (Tab. 1). En otros casos, una parte pasa a integrar la matriz de la escoria y la parte restante se reduce a metal y se asocia al cobre que se va obteniendo, formando nodulillos o masas en las que ambos metales

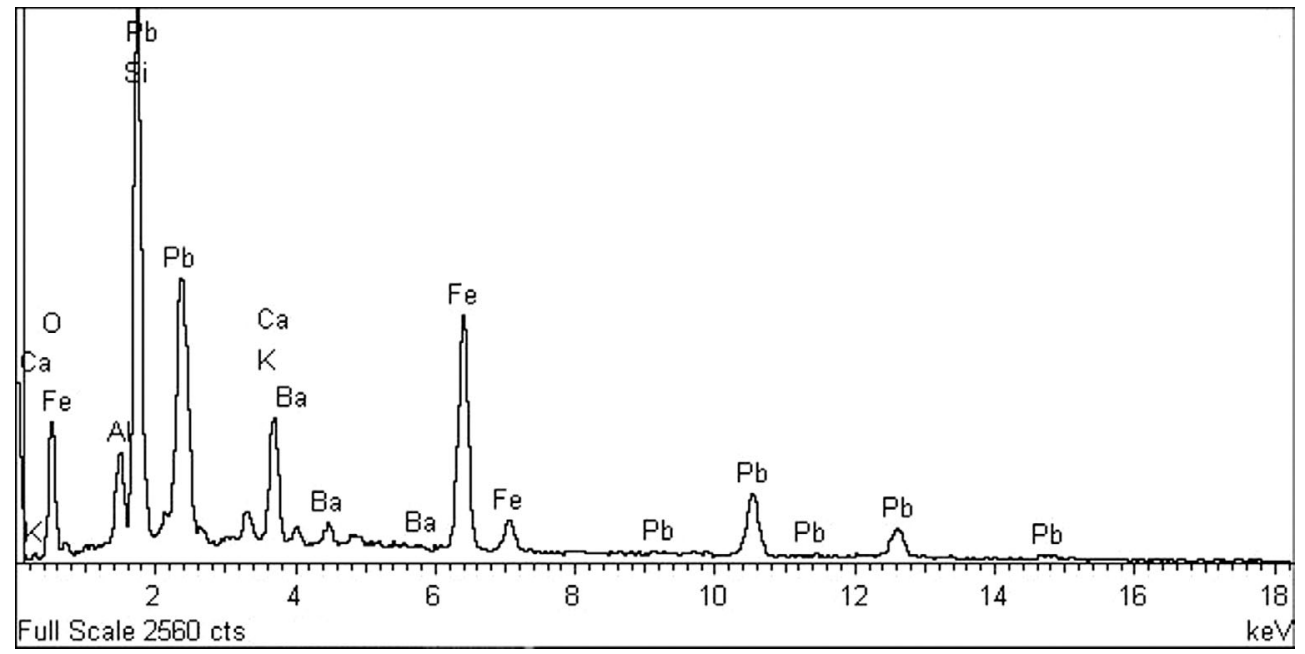

Fig. 11. Espectro XRF de la matriz vítrea de la escoria BE25078 procedente de Peñalosa.

\begin{tabular}{|c|c|c|c|c|c|c|}
\hline N. ${ }^{\circ}$ Análisis & N. ${ }^{0}$ Invent. & $\mathrm{Cu}$ & $\mathbf{P b}$ & $\mathbf{F e}$ & $\mathbf{N i}$ & As \\
\hline PA13668/2 & BE3125 & 91,8 & 6,6 & 1,62 & n.d. & n.d. \\
\hline PA13668/3 & BE3125 & 88,0 & 9,54 & 2,46 & n.d. & n.d. \\
\hline PA13668/4 & BE3125 & 94,3 & 3,99 & 1,67 & n.d. & n.d. \\
\hline PA13759/03 & BE25078 & 69,1 & 6,3 & 3,26 & 0,66 & 16,9 \\
\hline PA13760/2 & BE34019a & 96,4 & n.d. & n.d. & n.d. & 2,54 \\
\hline PA13760/4 & BE34019a & 96,8 & n.d. & 0,56 & n.d. & 1,94 \\
\hline PA13760/5 & BE34019a & 96,3 & n.d. & 0,62 & n.d. & 2,34 \\
\hline PA14052/04 & BE34019 & 16,6 & 83,4 & n.d. & n.d. & n.d. \\
\hline PA14052/05 & BE34019 & 76,5 & 23,5 & n.d. & n.d. & n.d. \\
\hline PA14052/06 & BE34019 & 93,7 & 6,3 & n.d. & n.d. & n.d. \\
\hline PA14052/07 & BE34019 & 94,8 & 4,1 & n.d. & n.d. & n.d. \\
\hline PA14055/4 & BE17476 & 97,6 & 1,48 & 0,91 & n.d. & n.d. \\
\hline PA14055/5 & BE17476 & 91,9 & 1,65 & 2,59 & n.d. & n.d. \\
\hline PA14055/7 & BE17476 & 98,5 & 1,06 & 0,44 & n.d. & n.d. \\
\hline PA14056/4 & BE15346 & 95,4 & 4,41 & n.d. & n.d. & n.d. \\
\hline PA14057/08 & BE13228 & 97,5 & n.d. & 2,47 & n.d. & n.d. \\
\hline PA14057/10 & BE13228 & 99,4 & n.d. & 0,57 & n.d. & n.d. \\
\hline PA14060/3 & BE13309-2 & 96,4 & n.d. & 3,63 & n.d. & n.d. \\
\hline PA14060/4 & BE13309-2 & 93,9 & 1,92 & 4,13 & n.d. & n.d. \\
\hline BE28275-2/2 & BE28275-2 & 99,0 & n.d. & 0,98 & n.d. & n.d. \\
\hline BE28275-2/3 & BE28275-2 & 98,5 & n.d. & 1,48 & n.d. & n.d. \\
\hline BE28275-2/7 & BE28275-2 & 98,9 & n.d. & 1,07 & n.d. & n.d. \\
\hline
\end{tabular}

Tab. 1. Composición química de algunas bolitas de metal atrapadas en las escorias cobre-plomo de Peñalosa (microsonda MEB, $\%$ en peso). Abreviaturas: n.d. elemento $=$ no detectado. 
aparecen juntos pero segregados, dada su poca solubilidad mutua (Tab. 1). La figura 12 muestra gráficamente esta segunda categoría.

No deja de ser interesante señalar que, a pesar de haber tanto plomo en los minerales, no hemos observado que se forme plomo metálico aislado en ninguna de las escorias analizadas. En la muestra BE34019 una de las inclusiones metálicas llega a tener un $83 \%$ de plomo, pero contiene también cobre. Aunque no es éste ni el momento ni el lugar para entrar en tan interesante cuestión que nos acercaría a esa incógnita tecnológica que plantean el plomo y los bronces plomados en la Prehistoria Reciente, viene bien recordar los experimentos de Roger Hetherington reduciendo galena. Según este autor, resulta fácil extraer el plomo de la galena (Hetherington 1991: 32), sin embargo, las condiciones en las que se realizaron tales experimentos (cuyos resultados nunca fueron publicados detalladamente) no son extrapolables a las que se deducen de las escorias de Peñalosa. Queda así abierta una vía de experimentación prácticamente virgen.

Las escorias de cobre no presentan ninguna particularidad digna de mención para los objetivos de este artículo, y coinciden con lo visto

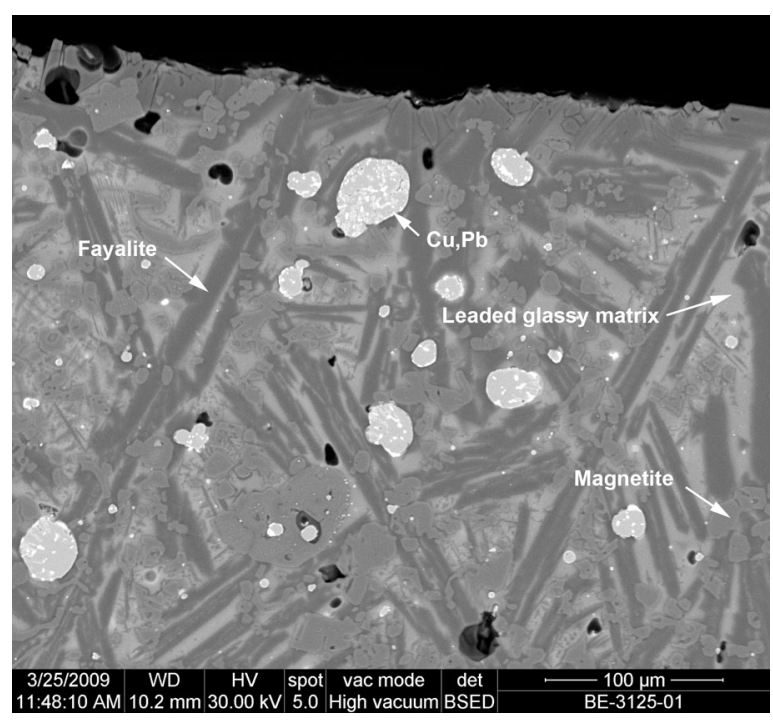

Fig. 12. Imagen obtenida en el MEB (electrones retrodispersados) de la escoria BE3125 procedente de Peñalosa. En la matriz vítrea plomada (glassy leaded matrix) con cristales aciculares de fayalita (fayalite) han quedado atrapadas numerosas bolitas metálicas $(\mathrm{Cu}, \mathrm{Pb})$ de cobre (color gris) y plomo (color blanco). Nótese la abundancia de magnetita (magnetite). en otros estudios de escorias producidas con tecnologías primitivas (Müller et al. 2004; Hauptmann 2003; Rovira 2002; Keesmann y Moreno 1999).

Una última característica a destacar de las escorias de Peñalosa es la notable retención de cobre bien como cobre metálico, bien como compuestos minerales. Los análisis por XRF mencionados al iniciar este apartado, señalan pérdidas que oscilan entre el $0,51 \%$ y el $31 \% \mathrm{Cu}$ (Fig. 13), otro rasgo que encontramos en la tecnología primitiva de obtención de cobre (Hauptmann 2003: 461-462). La elevada viscosidad de la escoria debida al material sin fundir impide la buena separación de la fase metálica, que queda atrapada en la masa semisólida que se va formando en la cámara de reacción.

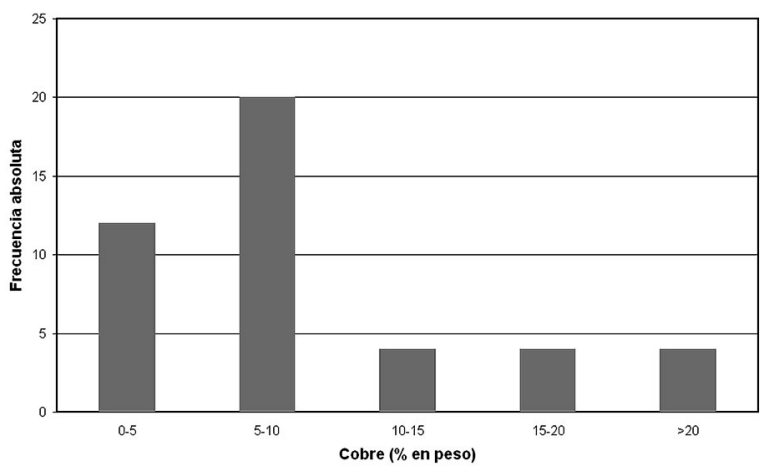

Fig. 13. Histograma representando las pérdidas de cobre en las escorias de Peñalosa, según los resultados de los análisis por XRF.

\section{CERÁMICAS DE USO METALÚRGICO}

Los vasos cerámicos relacionados con la metalurgia (Fig. 14) están ampliamente representados en todos los ámbitos del yacimiento, lo cual resulta indicativo de la importancia y profusión de esta actividad además de su incidencia socio-económica dentro del poblado. De la gran cantidad de restos arqueometalúrgicos se infiere igualmente una producción metálica que rebasa los límites del autoconsumo, por lo que probablemente en su mayor parte saliese del poblado en forma de lingotes.

A partir de los fragmentos cerámicos más grandes y de los vasos completos, se realizó un 


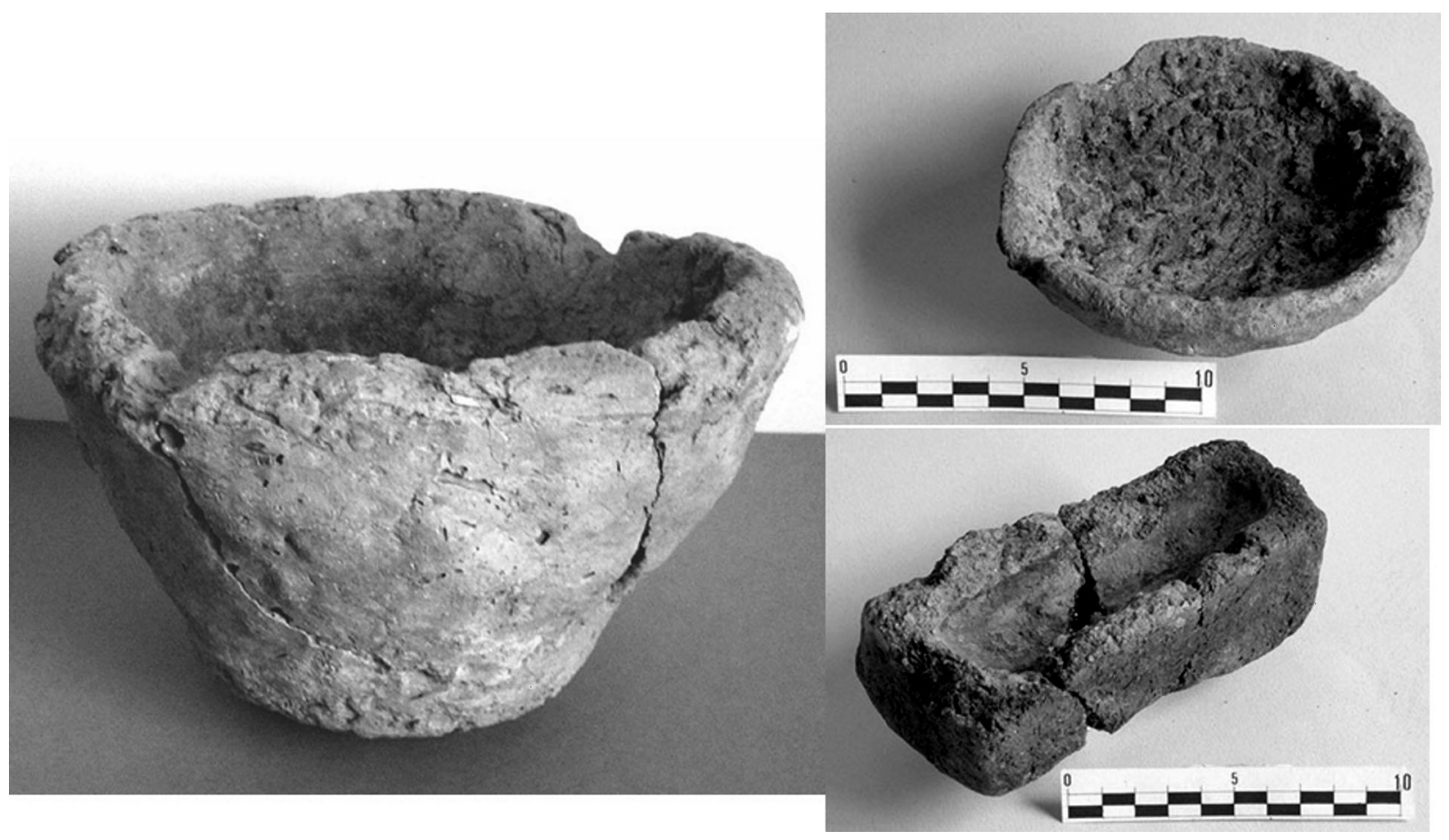

Fig. 14. Vasijas cerámicas de uso metalúrgico (la vasija honda tiene un diámetro de aprox. $24 \mathrm{~cm}$ ) y un molde procedentes del yacimiento de la Edad del Bronce de Peñalosa (Baños de la Encina, Jaén).

estudio morfométrico multivariable de la cerámica utilizada en la metalurgia de Peñalosa (Contreras y Cámara 2000): se pudieron establecer hasta cuatro grupos tipológicos diferentes que responden a las categorías de vasijas planas, vasijas hondas, moldes y piezas circulares. A ellos habría que añadir los posibles fragmentos de pared de horno y una pieza que puede ser considerada un fragmento de boquilla de soplado. Los tres primeros grupos tipológicos han sido muestreados y analizados para la caracterización de la pasta cerámica en todos sus compuestos (Cortés 2007: 64-66). Las conclusiones de este estudio avanzan en la idea de que existe una intencionalidad manifiesta en la elección de la arcilla y en la adición de determinado tipo, tamaño y cantidad de desgrasantes en lo que respecta al menos a la elaboración de las vasijas planas y las hondas. En el primer caso predomina la materia orgánica y en el segundo caso los cuarzos. Esta idea debe de estar en relación con la función o el uso que tengan que desempeñar cada uno de ellos en los procesos metalúrgicos, según los resultados obtenidos que se expondrán en un estudio próximo.

\subsection{Vasijas planas}

Las vasijas planas tienen formas abiertas tipo cuenco, generalmente de casquete esférico o semiesférico, cuyo fondo puede ser convexo, en la mayoría de los casos, o plano. En función del fondo se han podido distinguir hasta 4 subtipos diferentes, atendiendo fundamentalmente al diámetro de boca, la altura total y el ángulo del borde en relación con la abertura de las paredes. Cabe destacar la existencia, aunque muy escasa, de vasijas de fondo aplanado, de pequeñas dimensiones y paredes muy rectas.

Como características generales y comunes a todas, se puede señalar: un grosor que oscila entre 1 y $2,5 \mathrm{~cm}$; ambas superficies toscamente alisadas; presencia en la cara interna de una capa uniforme de escoria, de entre $0,2-1 \mathrm{~cm}$ de grosor que a veces excede el borde. En su interior presentan una intensa vitrificación que en numerosas ocasiones penetra hasta $2-3 \mathrm{~mm}$ en la matriz de la cerámica.

En cuanto a las diferencias morfométricas, las vasijas planas de fondo convexo oscilan entre 
100 y $170 \mathrm{~mm}$ de diámetro de borde, la altura varía entre 20 y $60 \mathrm{~mm}$ y la abertura de boca entre $125^{\circ}$ y $153^{\circ}$, mientras que las de fondo plano, por lo general de menor tamaño, presentan aproximadamente $100 \mathrm{~mm}$ de diámetro de boca, el fondo es de unos $80 \mathrm{~mm}$ de diámetro, tienen paredes rectas, una altura media de $40 \mathrm{~mm}$ y entre $104^{\circ}$ y $113^{\circ}$ de abertura de boca.

Otro dato que caracteriza sobre todo a las vasijas planas de fondo convexo, es la presencia de pico vertedero; la mayor parte de los ejemplares completos recuperados pertenecen a este tipo.

En cuanto a la caracterización de la pasta cerámica, este grupo tipológico presenta dos tipos distintos. La primera es una pasta arcillo-limosa, de textura grosera y escasa porosidad; los desgrasantes minerales son fundamentalmente cuarzo y cuarcita, aunque se han identificado otros en menor proporción, como feldespatos, micas y esquistos. Aproximadamente el $50 \%$ de la pasta está ocupada por desgrasantes de tamaño medio y fino, y tiende a ser heterométrica.

El segundo tipo de pasta cerámica se caracteriza por una mayor heterogeneidad de los minerales usados como desgrasantes. Aunque el cuarzo siempre es dominante, la pasta incluye cantidades mayores de otros minerales como feldespatos, micas y plagioclasas. Los desgrasantes en general son de tamaño medio y fino, aunque los gruesos tienen una mejor representación en algunos fragmentos. En general, este tipo de pasta cerámica es exclusiva de las vasijas planas.

\subsection{Vasijas hondas}

Son un tipo de vasija más profunda que las anteriores, con mayor grosor de las paredes, alrededor de 3-4 cm, y del fondo que mide unos $5 \mathrm{~cm}$. A diferencia de las anteriores, la capa de escoria que presentan en la superficie interna tiende a ser muy fina, siendo en algunos casos muy irregular e incluso inexistente.

Se han distinguido dos tipos: vasijas hondas de fondo plano y vasijas hondas de forma compuesta con tres subtipos diferentes en función de los límites métricos que presenten respecto al diámetro de boca, diámetro máximo del cuerpo, altura total, altura de la inflexión y ángulo del borde. Las características morfométricas muestran un diámetro de boca de 140 a $420 \mathrm{~mm}$, una altura total de 61 a $107 \mathrm{~mm}$ y un ángulo del borde de entre $91^{\circ}$ y $131^{\circ}$.

Prácticamente en todas el labio es aplanado, siendo usual la presencia de una o dos impresiones hechas con un instrumento romo, una técnica exclusiva de estos vasos ya que no existe en el resto de cerámicas domésticas ni de almacenamiento halladas en el yacimiento. Algunas vasijas presentan también pico vertedero.

La pasta cerámica de este grupo tipológico destaca sobre todo por la utilización intencionada de materia vegetal como desgrasante, además presenta una textura más fina, arcillosa, muy porosa y mucho más magra, junto con una distribución más homogénea de los desgrasantes; los de origen mineral no suelen superar los $2 \mathrm{~mm}$, siendo los desgrasantes gruesos muy escasos.

En general los desgrasantes minerales suelen alternarse con los orgánicos que, en la mayoría de los casos, son más numerosos que los primeros, y la pasta se subdivide en dos tipos diferentes según la mayor o menor cantidad de unos u otros. El desgrasante mineral más utilizado es cuarzo, seguido de cuarcita, feldespatos, mica, esquistos rojos y grises.

Entre otras características destaca el color anaranjado de la pasta en su exterior, tornándose gris en las zonas más internas expuestas a las altas temperaturas. La vitrificación producida por el calor en la superficie interna no es tan intensa como la que se observa en la cerámica de las vasijas planas. Parece que las vasijas hondas recibían el fuego sólo por el interior, mientras que las planas por lo general suelen mostrar también las superficies externas alteradas térmicamente.

\subsection{Moldes}

Los moldes cerámicos están presentes en una elevada proporción dentro del conjunto material metalúrgico, hallándose algunos completos. Aunque todos responden a la misma tipología, su morfología ha permitido diferenciar dos subtipos. Son contenedores de forma más o menos trapezoidal de fondo plano y paredes rectas, de los que saldrían unos lingotes rectangulares o trapezoidales (Fig. 14).

En cuanto a la caracterización de la pasta cerámica, este grupo es el de mejor factura. La pasta, arcillo-limosa y de porosidad media, es grosera y similar a la del grupo de las vasijas planas, pero 
de factura más cuidada. El desgrasante es de tamaño medio-fino, con predominio de este último; en general, presenta formas redondeadas y está formado por cuarzo, cuarcita, feldespatos y mica.

Normalmente en los moldes no se han observado restos de materia orgánica.

\subsection{Análisis de las escorificaciones}

Como es sabido, las vasijas cerámicas tienen dos funciones básicas en la metalurgia: servir como vasijas de reducción y como crisoles para fundir metal. En ocasiones a partir de su morfología no es sencillo determinar a cuál de las dos funciones se destinó una vasija. Tampoco el tamaño es un argumento decisivo, si bien es cierto que, dadas las limitaciones pirometalúrgicas prehistóricas, no era posible mantener en estado líquido una masa de metal excesivamente grande. Ello sugiere que el crisol para fundir debía ser de menor tamaño que la vasija de reducción. Pero, como veremos, hay vasijas pequeñas que fueron utilizadas para reducir mineral aunque su tamaño es apropiado para funcionar bien como crisol. El único modo de aproximarnos con cierta seguridad a una correcta clasificación funcional es mediante el estudio científico de las escorificaciones residuales en las paredes de dichas vasijas.

Las escorificaciones que se forman en la cara interna de las vasijas se deben a las reacciones que tienen lugar, a alta temperatura, entre el material contenido y los componentes de la pasta cerámica. En las vasijas de reducción el contenido es el mineral metalífero con su ganga acompañante y la ceniza que se va formando por la combustión del carbón. En cambio, en un crisol el contenido es cobre metálico y la ceniza de combustión. Esta primera consideración ya permite presuponer que las escorificaciones de las vasijas de reducción van a tener composiciones más complejas que las de los crisoles. Esto, que en general es cierto, no excluye la posibilidad de que el metal introducido en el crisol fuera cobre bruto con algo de escoria, lo cual daría lugar a una escorificación de composición compleja. Ahora bien, lo que no cabe pensar es que en el crisol para fundir metal se introdujera mineral sin reducir. Por tanto, la presencia en la escorificación de un vaso de relictos de mineral es un argumento bastante sólido para considerar su uso en tareas de reducción. Su ausencia, en cambio, no es argu- mento suficiente para rechazar esa función, como es obvio.

Por otro lado, la duración de un proceso de reducción de mineral es mucho mayor que el tiempo necesario para fundir el metal, según se ha comprobado en numerosos experimentos (por ej. Rovira 1999: 109). Por tanto, el recipiente cerámico se encuentra expuesto a temperaturas elevadas durante mucho más tiempo en el primer caso que en el segundo, dando lugar a mayores posibilidades de reacciones químicas entre contenido y continente.

Se han analizado por XRF medio centenar de vasijas con escorificaciones para determinar la composición elemental de la escoria. De ellas, se han seleccionado diez para estudios más detallados en el MEB.

Las escorificaciones en vasijas de reducción reproducen con total exactitud lo visto en las escorias: algunas indican que el mineral procesado contenía sólo cobre y otras se deben a la reducción de minerales cobre-plomo. Un ejemplo de las primeras, puede verse en la imagen MEB de la escorificación BE10168-1 (Fig. 15): una matriz vítrea silicatada en cuyo seno se han formado bastones de fayalita; se aprecian bolitas de cobre atrapadas en la escoria. En otras regiones de esta

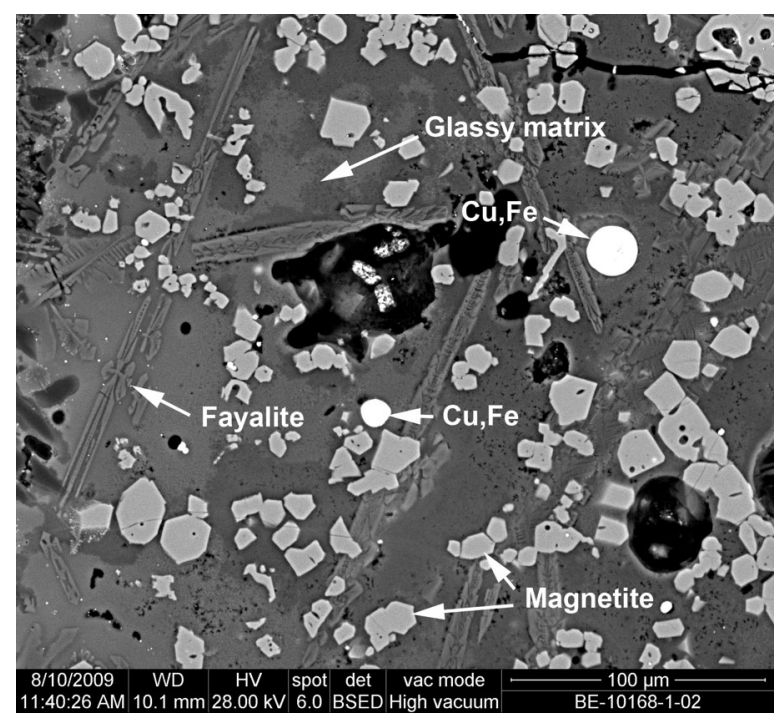

Fig. 15. Imagen obtenida en el MEB (electrones retrodispersados) de la escorificación en la vasija de reducción BE10168-1 procedente de Peñalosa. En la matriz (glassy matrix) se aprecian formaciones de fayalita (fayalite) y bolitas de cobre. Nótese la abundancia de magnetita (magnetite). 
misma muestra se localizan cristales de diópsido y algunas inclusiones esféricas de sulfuro de cobre, cuya presencia sugiere la reducción de minerales mixtos óxidos-sulfuros de cobre de los que ya hemos hablado en el apartado correspondiente a los minerales.

Otra interesante muestra (Fig. 16) corresponde a la escorificación de una vasija de reducción en la que se procesaron minerales de cobre-plomo. La matriz es un vidrio plomado en la que destacan cristales de anortita. El cobre atrapado tiene una composición polimetálica $\mathrm{Cu}-\mathrm{Pb}-\mathrm{As}-\mathrm{Fe}$, conteniendo cantidades de arsénico que llegan al $30 \%$ As y plomo de hasta $80 \% \mathrm{~Pb}$ en algunas bolitas.

La presencia en estas escorificaciones de compuestos minerales como delafosita, magnetita y algunos reductos de fayalita, indican unas condiciones de fugacidad de oxígeno variables que hacen que el ambiente redox oscile constantemente de oxidante a reductor, algo que ya habíamos comentado al hablar de las escorias. Así, pues, las escorias y las vasijas de reducción de Peñalosa delinean un sistema tecnológico unitario para la obtención de cobre de rasgos primitivos, según la clasificación establecida por Hauptmann (2003: 461-462).

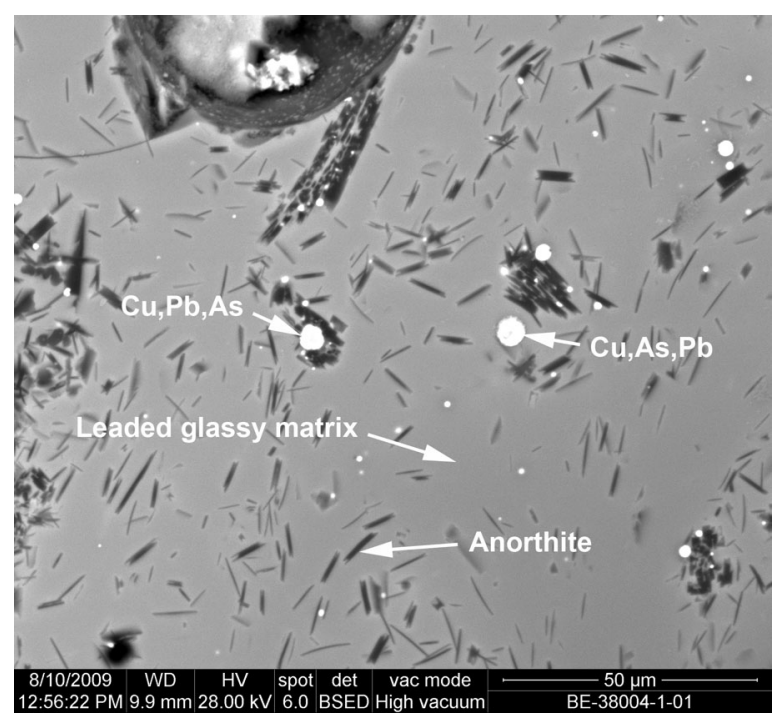

Fig. 16. Imagen obtenida en el MEB (electrones retrodispersados) de la escorificación en la vasija de reducción BE38004-1 procedente de Peñalosa. La matriz (leaded glassy matrix) se muestra aquí de un color gris mucho más brillante que en la figura 15 por la presencia de silicato de plomo. Se han formado bastones de anortita (anorthite) y el cobre obtenido muestra un acusado polimetalismo.
Las escorificaciones en los crisoles suelen ser más delgadas que en las vasijas de reducción y el contacto con la pared cerámica más nítido, como puede verse en la figura 17. En este caso se trata de una escorificación constituida por un vidrio al plomo que merece una explicación. En la tabla 2 veíamos cómo a partir de los minerales cobre-plomo se obtenía cobre con una cierta cantidad de plomo. El plomo es prácticamente insoluble en el cobre a cualquier temperatura, por lo que siempre se encuentra segregado. Su temperatura de fundición es relativamente baja $\left(327^{\circ} \mathrm{C}\right)$ comparada con los $1.083^{\circ} \mathrm{C}$ necesarios para fundir el cobre. Si en el crisol se cargan fragmentos o bolitas de cobre-plomo y se ponen a calentar para obtener un caldo, cuando se alcanzan los $327^{\circ} \mathrm{C}$ el cobre comienza a exudar el plomo que contiene. El plomo es un metal que se oxida fácilmente a alta temperatura y el óxido de plomo (litargirio) reacciona con facilidad con la sílice de la arcilla de la pared del crisol dando lugar a un silicato de plomo. Cuando en el crisol se alcanza la temperatura de fusión del cobre, la mayor parte del plomo acompañante se habrá desprendido y habrá formado la escorificación de la pared del crisol. El metal resultante es un cobre refinado que ha perdido casi todo el plomo que contenía.

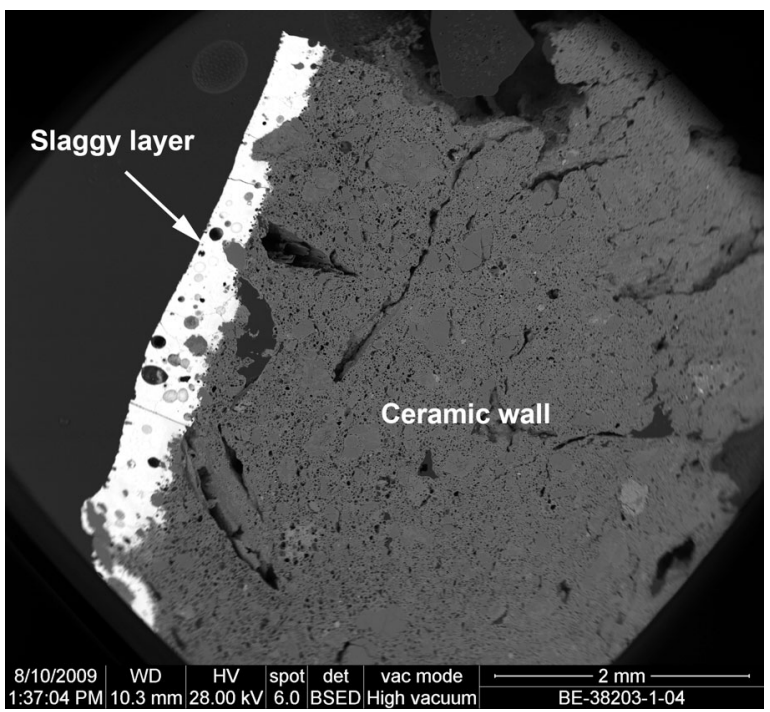

Fig. 17. Imagen obtenida en el MEB (electrones retrodispersados) de una sección de la pared del crisol BE38203-1 procedente de Peñalosa. Obsérvese la delgada capa blanca escorificada (slaggy layer) y la nítida separación respecto a la pared del crisol (ceramic wall). 


\section{METAL BRUTO Y OBJETOS DE METAL DE PEÑALOSA}

Las espectrometrías por fluorescencia de rayos X (XRF) de los objetos de metal y restos de fundición de Peñalosa documentan dos tipos de metal: cobre generalmente acompañado de arsénico y bronce con estaño (Tab. 2).

El empleo de cobre arsenicado resulta coherente con las analíticas de las escorias y escorificaciones en las cerámicas metalúrgicas (ver los análisis de inclusiones de metal retenido en las escorias de la tabla 1). Allí veíamos dos tipos de cobre, con y sin plomo en su composición, según se obtuviera de minerales de cobre o de cobre-plomo. También puede apreciarse cómo, por término medio, el cobre plomado bruto retenido en la escoria contiene más plomo que el cobre refinado con el que se han fabricado los objetos, de acuerdo con el mecanismo de refino explicado en párrafos anteriores.

La presencia de arsénico en tasas que alcanzan el $14 \%$ As en el puñal PA14034 (Tab. 2) merece mayor reflexión. Se ha venido defendiendo a partir de datos analíticos que la mineralogía compleja de muchas de las mineralizaciones cupríferas de la Península Ibérica es la causa de la aparición de los bronces naturales cobre-arsénico desde los primeros peldaños de la metalurgia calcolítica (Castaño et al. 1991: 50-51; Rovira 2004: 16-19). Dos de las escorias analizadas de Peñalosa justifican esa idea (PA13759 y PA13760 en la Tab. 1). Asimismo, uno de los restos de fundición de cobre bruto también habla en el mismo sentido (PA14061 en la Tab. 2). Pero sería de desear dis- poner de más datos analíticos en un futuro, ya que para esta primera aproximación se ha centrado el estudio en los subproductos cobre-plomo por representar una metalurgia primaria totalmente desconocida hasta ahora.

La presencia de bronces cobre-estaño en contextos argáricos ya no es una novedad en cuanto a análisis de objetos (Montero 1994), pero su tecnología de obtención todavía resulta enigmática en muchos sentidos, aunque comienzan a aflorar ciertas sugerencias al respecto que apuntan a la co-reducción de minerales o la cementación de metal con casiterita (Rovira 2008-2009). Se conocen varias piezas de bronce binario de Peñalosa, pero no se ha analizado por el momento ningún vestigio que abogue en favor de su producción local.

En líneas generales, los nuevos datos analíticos referidos a objetos aquí presentados coinciden con las composiciones determinadas en análisis previos (Moreno 2000: 218, Tab. 9.1)

\section{CONCLUSIONES}

En la memoria final de la primera fase del Proyecto Peñalosa (Contreras 2000) se realizó una primera propuesta basada en la interpretación de los datos analíticos disponibles en aquel momento. Ahora, con una visión físico-química más completa de los procesos metalúrgicos, estamos en condiciones de ampliar las conjeturas avanzadas anteriormente.

1. Durante la vida del poblado se explotaron al menos dos tipos de mineralizaciones cuprífe-

\begin{tabular}{|l|l|l|c|c|c|c|c|c|c|c|c|}
\hline \multicolumn{1}{|c|}{ N. $^{\circ}$ Análisis } & \multicolumn{1}{|c|}{ N. $^{{ }^{2} \text { Invent. }}$} & \multicolumn{1}{|c|}{ Objeto } & $\mathbf{C u}$ & $\mathbf{P b}$ & $\mathbf{A s}$ & $\mathbf{S n}$ & $\mathbf{F e}$ & $\mathbf{N i}$ & $\mathbf{Z n}$ & $\mathbf{A g}$ & $\mathbf{S b}$ \\
\hline PA13632 & BE14/1023 & Hacha plana & 99,7 & n.d. & 0,31 & n.d. & n.d. & n.d. & n.d. & n.d. & n.d. \\
PA13967A & BE38203-1 & Resto fundic. & 88,1 & 11,0 & 0,24 & 0,030 & 0,12 & n.d. & n.d. & 0,414 & 0,098 \\
PA14032 & BE20232 & Punzón & 98,7 & 0,58 & 0,66 & 0,040 & n.d. & n.d. & n.d. & 0,049 & 0,018 \\
PA14033 & BE28558 & Punta & 97,8 & n.d. & 2,12 & 0,020 & n.d. & n.d. & n.d. & 0,016 & n.d. \\
PA14034 & BE25089 & Puñal & 85,2 & 0,13 & 14,7 & 0,010 & n.d. & n.d. & n.d. & 0,016 & 0,016 \\
PA14036 & BE28094 & Punzón & 97,6 & 0,61 & 1,70 & n.d. & 0,12 & n.d. & n.d. & n.d. & n.d. \\
PA14047 & BE28880 & Puñal (frag.) & 96,3 & n.d. & 3,55 & n.d. & 0,10 & n.d. & n.d. & n.d. & 0,027 \\
PA14048 & BE10209-5 & Punzón & 98,6 & n.d. & 1,41 & n.d. & n.d. & n.d. & n.d. & tr & n.d. \\
PA14049 & BE10155 & Puñal & 97,4 & 0,12 & 2,30 & 0,03 & 0,10 & n.d. & n.d. & tr & 0,001 \\
PA14050 & BE25040 & Puñal (frag.) & 89,6 & 0,57 & 0,40 & 9,40 & tr & n.d. & n.d. & n.d. & 0,035 \\
PA14051 & BE28210 & Puñal & 97,3 & 0,20 & 2,37 & 0,030 & 0,12 & n.d. & n.d. & n.d. & n.d. \\
PA14053 & BE38221 & Punzón & 97,3 & 0,91 & 1,45 & 0,040 & 0,27 & n.d. & n.d. & 0,003 & 0,010 \\
PA14061 & BE44003 & Masa de metal & 97,8 & 0,17 & 1,76 & 0,03 & 0,17 & n.d. & n.d. & 0,030 & 0,011 \\
\hline
\end{tabular}

Tab. 2. Composición química de los objetos de Peñalosa (XRF, \% en peso). Abreviaturas: n.d. elemento = no detectado; $\operatorname{tr}=$ elemento detectado a nivel de trazas no valorables. 
ras: las que proveían de minerales de cobre y aquellas otras que junto con el cobre también tenían plomo. Los análisis de isótopos de plomo de algunas muestras de minerales parecen indicar claramente que éstos proceden al menos de dos minas cercanas al yacimiento: la mina de El Polígono y la de José Martín Palacios. Son minerales en los que frecuentemente encontramos asociaciones de variedades oxidadas (malaquita, azurita, cuprita) y sulfurosas (covellita, calcopirita, galena). En la última mina señalada, además se ha podido documentar la técnica utilizada para la extracción del mineral: la fragmentación del metalotecto por la acción continuada de fuego más agua, lo que facilita enormemente la tarea.

2. Los análisis de las escorias muestran una dinámica similar a la ofrecida por los minerales, unas contienen cantidades importantes de plomo y otras no. Su composición química y mineralógica se corresponde con escorias inmaduras, con abundante sílice libre, de elevada viscosidad y que retienen mucho cobre, bien en forma metálica bien como minerales sin reducir. Ello permite clasificarlas como subproductos de una tecnología primitiva de obtención de cobre caracterizada por la reducción directa de los minerales sin el empleo de fundentes que mejorarían el rendimiento de la reducción y la separación del metal. Catalogarla como "tecnología primitiva" no es en modo alguno peyorativo, ni tiene relación alguna con la producción de metal sino con el modo de producir el metal. Dada una cantidad determinada de mineral, usando una tecnología primitiva la extracción completa del metal que contiene requiere varios procesos de reducción consecutivos, pero sólo uno empleando una tecnología desarrollada. Dicho de otro modo, para satisfacer una determinada demanda de metal son necesarias muchas más instalaciones productoras en un caso que en otro, siendo el producto final el mismo. Un aspecto interesante, en suma, es el aprovechamiento de minerales con plomo, que resulta del todo novedoso para la metalurgia de la Edad del Bronce.

3. En el conjunto de materiales arqueometalúrgicos de Peñalosa existen otros argumentos que apuntan hacia la tecnología primitiva. El empleo de vasijas cerámicas como recipientes reactores es sin duda el más sólido, supliendo de ese modo la ausencia de verdaderos hornos metalúrgicos. Hay que señalar igualmente que la variedad tipológica de dichas cerámicas abre camino hacia una cierta especialización de la producción metalúrgica. Futuros trabajos en los que se muestre la seriación cronológica de dichos tipos servirán para poder dibujar con trazos firmes la dirección del proceso evolutivo.

4. Estas cerámicas metalúrgicas, aún sin entrar en la categoría de refractarias, sí que se diferencian en cuanto a composición, tamaño y tipo de desgrasante empleado en su manufactura, de las restantes cerámicas de carácter doméstico. La composición de las pastas de algunos de estos fragmentos (Fig. 18) muestra que sólo uno de ellos, correspondiente a una vasija de reducción, se aproxima a la zona de arcillas con buenas propiedades refractarias. Ello, lejos de interpretarse en sentido negativo, reitera que dichas cerámicas cumplen su cometido a la perfección sin deformarse, es decir, para su función no requieren de mayor resistencia a altas temperaturas ya que, como hemos señalado anteriormente al mencionar las temperaturas de formación de las escorias, difícilmente se superaban los $1.200^{\circ} \mathrm{C}$ en la zona de reacción.

5. La ausencia de toberas en Peñalosa plantea como alternativa el uso de tubos de soplado a pulmón, de cuya eficacia nos hablan los paralelos etnográficos y no pocos trabajos experimentales. De esta forma, y dado que la actividad metalúrgi-

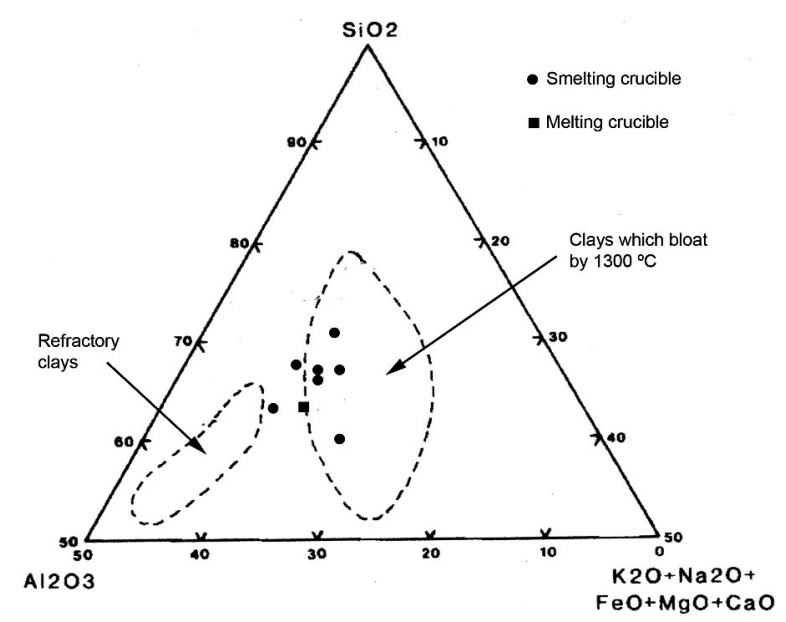

Fig. 18. Diagrama ternario representando la composición de las vasijas de reducción (smelting crucibles) y los crisoles (melting crucibles) de Peñalosa en relación con sus cualidades refractarias. Las flechas señalan las áreas de las cerámicas refractarias (refractory clays) y de las cerámicas comunes que se deforman a $1.300^{\circ} \mathrm{C}$ (clays which bloat by $1,300^{\circ} \mathrm{C}$ ). Diagrama según Riley (1951: 123, Fig. 1), modificado. 
ca se desarrollaba en el interior del poblado, los metalúrgicos pudieron alcanzar la temperatura necesaria que hiciese rentable la reducción. Hasta el momento tan solo se ha recuperado una de las boquillas de cerámica que, sujetas al extremo del tubo o caña, quedan más expuestas a las brasas. Se trata del extremo de una boquilla fragmentada, con una perforación de unos $10 \mathrm{~mm}$ de diámetro, adecuada para producir un chorro de aire a presión con la fuerza de los pulmones (Moreno 2000: 184, Fig. 9.2.2). Sin embargo, a este respecto, si correlacionamos el volumen de restos metalúrgicos de todo tipo con el único ejemplar de boquilla de soplado proporcionado por el registro arqueológico, hemos de ser cautelosos.

6. La vocación metalúrgica del poblado viene avalada asimismo por la existencia de lingotes de cobre de forma circular plano-convexa (Moreno 2000: 209-211). El lingote, como acumulación de metal para su empleo diferido, determina una producción excedentaria y con perspectivas de un intercambio local o a más amplio recorrido. En una versión negativa, igualmente podemos pensar en limitaciones tecnológicas del momento atendiendo a su peso y tamaño. Dichos lingotes, con un peso que oscila entre los 135 y $250 \mathrm{~g}$ y con un diámetro máximo de entre 4,9 y $5,7 \mathrm{~cm}$, quizás nos informen de cierta dificultad para mantener en estado líquido coladas de cobre de mayor volumen, lo cual limitará el tamaño máximo de los objetos a fabricar o requerirá la sincronización de dos o más crisoladas.

7. Como ya se había indicado en los primeros estudios sobre la metalurgia de Peñalosa (Moreno 2000), restos de reducción y fundición aparecen en prácticamente todos los espacios domésticos del poblado, con fragmentos de vasijas metalúrgicas en cada uno de los contextos espaciales, lo cual indica una producción intensiva de cobre por parte de la mayoría de la población. Ambas tareas aparecían definidas de manera simplificada en anteriores trabajos en los que, por simple y pura deducción lógica basada en valores morfométricos y formales, se relacionaba las vasijas hondas con operaciones de reducción de mineral y las vasijas planas con la fundición de metal. Se asumió que fuera más idóneo fundir en un crisol plano que en una vasija honda, y además la mayoría de los vasos planos estaban dotados de pico vertedero -que facilitaría el vertido del caldo metálico en los moldes- mientras sólo pocos ejemplares de los hondos lo presentan.
Sin embargo, los análisis realizados vienen a determinar lo contrario, por lo que será necesario ampliar el estudio analítico a la totalidad de muestras para caracterizar adecuadamente su funcionalidad. Así, las escorificaciones internas de las vasijas hondas apuntan a un uso como crisoles de fundición, mientras que la mayoría de las vasijas planas muestran escorificaciones internas con relictos de mineral sin reducir junto a minerales de cobre o cobre-plomo ya procesados, siendo por tanto vasijas de reducción.

8. La aparición de estas cerámicas metalúrgicas en otros poblados de la cuenca del Rumblar (Contreras et al. 2008) y más recientemente en las excavaciones realizadas en el Castillo de Burgalimar (Baños de la Encina, Jaén) muestran la colonización de este valle en el Bronce Pleno con vistas a la explotación masiva de los minerales de cobre. En trabajos anteriores (Contreras 2000; Contreras y Cámara 2002) hemos considerado que los grandes centros políticos causantes de esta colonización habría que localizarlos en la Loma de Úbeda donde la excavación del casco urbano de Úbeda y Baeza parece mostrar la existencia de grandes poblados de esta época, en especial el Cerro del Alcázar de Baeza, donde han aparecido sepulturas con ricos ajuares (Zafra y Pérez 1992). Las élites de este poblado posiblemente controlarían la distribución del metal a través de los lingotes producidos en la cuenca del Rumblar.

\section{BIBLIOGRAFÍA}

Arboledas Martínez, L.; Contreras, F.; Moreno, A.; Dueñas, J. y Pérez, A.A. 2006: "La mina de José Martín Palacios (Baños de la Encina, Jaén). Una aproximación a la minería antigua en la cuenca del Rumblar". Revista Arqueología y Territorio 3: 179-195.

Blas Cortina, M.A. 2005: "Un témoinage probant de l'exploitation préhistorique du cuivre dans le nord de la Péninsule Ibérique: le complexe minier d'El Aramo (Asturias)". En P. Ambert y J. Vaquer (dirs.): La première métallurgie en France et dans les pays limitrophes. Carcassone 28-30 Septembre 2002. Actes du Colloque International. Mémoire XXXVII de la Société Préhistorique Française. Paris: $195-206$.

Castaing, J.; Mille, B.; Zink, A.; Bourgarit, D. y Ambert, P. 2005: "L'abbatage préhistorique au feu dans le district minier de Cabrières (Hérault): évidences par thermoluminiscence (TL)". En P. Ambert y J. Vaquer (dirs.): La première métallurgie en 
France et dans les pays limitrophes. Carcassone 28-30 Septembre 2002. Actes du Colloque International. Mémoire XXXVII de la Société Préhistorique Française. Paris: 53-61.

Castaño, P.; Delibes, G.; Fernández-Miranda, M.; Fernández-Posse, M.D.; Mariscal, B.; Martín, C.; Montero, I. y Rovira, S. 1991: “Application des métodes archéométriques pour l'analyse du Chalcolithic du Bassin de Vera (Almería, Espagne). Revue d'Archéométrie 15: 47-53.

Contreras Cortés, F. (coord.) 2000: Análisis histórico de las comunidades de la Edad del Bronce del Piedemonte meridional de Sierra Morena y Depresión Linares-Bailén. Proyecto Peñalosa. Arqueología. Monografía 10. Dirección General de Bienes Culturales. Sevilla.

Contreras Cortés, F. 2004: "El grupo Argárico del Alto Guadalquivir". Primeras Jornadas La Edad del Bronce en tierras valencianas y zonas limitrofes (Villena 2002). Alicante: 493-503.

Contreras Cortés, F. y Cámara Serrano, J.A. 2000: “El poblado de la Edad del Bronce de Peñalosa (Baños de la Encina, Jaén). 4. La cerámica”. En F. Contreras (coord.): Análisis histórico de las comunidades de la Edad del Bronce del Piedemonte meridional de Sierra Morena y Depresión Linares-Bailén. Proyecto Peñalosa. Arqueología. Monografía 10. Dirección General de Bienes Culturales. Sevilla: 77-128.

Contreras Cortés, F. y Cámara Serrano, J.A. 2002: La jerarquización social en la Edad del Bronce del Alto Guadalquivir (España). El Poblado de Peñalosa (Baños de la Encina, Jaén. BAR Internacional Series 1025. Oxford.

Contreras, F.; Cámara, J.A.; Moreno, A. y Aranda, G. 2004: "Las sociedades estatales de la Edad del Bronce en el Alto Guadalquivir (Proyecto Peñalosa. 2.' Fase). V Campaña de Excavaciones (2001)". Anuario Arqueológico de Andalucía 2001, II: 24-38.

Contreras, F.; Dueñas, J.; Jaramillo, A.; Moreno, A.; Arboledas, L.; Campos, D.; García, J. y Pérez, A.A. 2005a: "Prospección Arqueometalúrgica de la cuenca media y alta del río Rumblar (Baños de la Encina, Jaén)". Anuario Arqueológico de Andalucía 2003, II: 22-36.

Contreras Cortés, F. y Moreno Onorato, A. e.p.: “La minería del cobre en época prehistórica en el alto Guadalquivir". Actas del V Simposio Internacional sobre Minería y Metalurgia Históricas en el Suroeste Europeo (León, 19-21 de junio de 2008). Universidad de León.

Contreras, F.; Moreno, A.; Dueñas, J.; Jaramillo, A.; García, J.A.; Arboledas, L.; Campos, D. y Pérez, A.A. 2005b: "La explotación minera de la cuenca del río Rumblar (Baños de la Encina, Jaén) en la Prehistoria Reciente". En O. Puche y M. Ayarzagüena (eds.): Actas del II Simposio sobre minería y metalurgia históricas en el Sudoeste europeo (Madrid 2004). Madrid: 115-120.

Contreras Cortés, F.; Rodríguez, M. ${ }^{\mathrm{a} O}$.; Cámara, J.A. y Moreno, A. 1997: Hace 4.000 años... Vida y muerte en dos poblados de la Alta Andalucía. Junta de Andalucía. Sevilla.

Cortés, H. 2007: "El papel de los elementos cerámicos en los procesos metalúrgicos. El caso de Peñalosa, grupo estructural VI". Revista Arqueología y Territorio, 4: 47-69.

Craddock, P.T. 1995: Early Metal Mining and Production. Edinburgh University Press. Edinburgh.

Domergue, C. 1987: Catalogue des mines et des fonderies antiques de la Péninsule Ibérique. Série Archaeologie VIII. Casa de Velázquez. Madrid.

Hauptmann, A. 2003: "Rationales of liquefaction and metal separation in earliest copper smelting: Basics for reconstructing Chalcolithic and Early Bronce Age smelting process". International Conference Archaeometallurgy in Europe. 24-25-26 September 2003. Milan, Italy. Proceeding 1. Associazione Italiana di Metallurgia. Milano: 459-468.

Hetherington, R. 1991: "Investigation into primitive lead smelting and its products". En W.A. Oddy (ed.): Aspects of early metallurgy. British Museum Occasional Paper 17. London: 27-40.

Hunt, M.; Contreras, F. y Arboledas, L. e.p.: "La procedencia de los recursos minerales metálicos en el poblado de la Edad de Bronce de Peñalosa (Baños de la Encina, Jaén). Resultados de análisis de isótopos de plomo". Actas del V Simposio Internacional sobre Minería y Metalurgia Históricas en el Suroeste Europeo (León 2008).

Keesmann, I. y Moreno, A. 1999: "Naturwissenschaftliche Untersuchungen zur frühen Technologie von Kupfer und Kupfer-Arsen-Bronze". En A. Hauptmann; E. Pernicka; T. Rehren y Ü. Yalçin (eds.): The Beginning of Metallurgy. Der Anschnitt 9. Bochum: 317-332.

Montero, I. 1994: El origen de la metalurgia en el sureste peninsular. Instituto de Estudios Almerienses. Almería.

Moreno Onorato, A. 2000: "La metalurgia de Peñalosa". En F. Contreras (coord.): Análisis histórico de las comunidades de la Edad del Bronce del Piedemonte Meridional de Sierra Morena y Depresión Linares-Bailén. Consejería de Cultura Arqueología monografías 10. Sevilla: 165-222.

Müller, R.; Rehren, T. y Rovira, S. 2004: "Almizaraque and the early copper metallurgy of Southeast Spain: New data". Madrider Miteilungen 45: 33-56.

Pittioni, R. 1951: "Prehistoric copper mining in Austria, problems and facts". Annual Report of Institute of Archaeology 7: 16-43.

Riley, C.M. 1951: "Relation of chemical properties to the bloating of clays". Journal of the American Ceramic Society 34: 121-128. 
Rovira, S. 1999: “Una propuesta metodológica para el estudio de la metalurgia prehistórica: el caso de Gorny en la región de Kargaly (Orenburg, Rusia)". Trabajos de Prehistoria 56 (2): 85-113.

Rovira, S. 2002: "Early slags and smelting byproducts of copper metallurgy in Spain". En M. Martelheim; E. Pernicka y R. Krause (eds.): Die Anfänge der Metallurgie in der Alten Welt) The Beginnings of Metallurgy in the Old World. Verlag Marie Leidorf GmbH. Rahden/Westf.: 83-98.

Rovira, S. 2004: "Tecnología metalúrgica y cambio cultural en la Prehistoria de la Península Ibérica”. Norba. Revista de Historia 17: 9-40.
Rovira, S. 2008-2009: "El bronce de la Edad del Hiero hispánica. Algunos aspectos de la tecnología y sus antecedentes". Boletín de la Asociación Española de Amigos de la Arqueología (Homenaje al Dr. Michael Blech) 45: 35-49.

Timberlake, S. 2003: "Early mining research in Britain: The development of the last ten years". En P. Craddock y J. Lang: Mining and Metal Production Through the Ages. The British Museum Press. London: 20-42.

Zafra, N. y Pérez, C. 1992: Excavaciones en el Cerro del Alcázar de Baeza. Campaña de 1991, Anuario Arqueológico de Andalucía 1991 III. Sevilla: 294-303. 